\title{
Hierarchical structure in the activities of daily living and trajectories of disability prior to death in elderly Chinese individuals
}

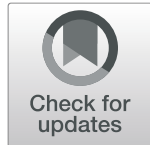

Yaofeng Han ${ }^{1,2}$, Jihui Xue', Wei Pei ${ }^{1}$ and Ya Fang ${ }^{1 *}$

\begin{abstract}
Background: The global burden of disability continues to increase. Understanding the hierarchical structure of activities of daily living $(A D L)$ and the trajectories of disability of elderly individuals is pivotal to developing early interventions.
\end{abstract}

Purpose: To determine the hierarchical structure of the ability of Chinese elderly individuals to perform ADL and further describe the trajectories of disability prior to death.

Methods: Longitudinal item response theory model (LIRT) was constructed for 28,345 elderly participants in the Chinese Longitudinal Healthy Longevity Survey, in which ADL were measured using the Katz scale from 1998 to 2018, until the participants' death. Two difficulty parameters ( $K_{-}$partial and $K_{-}$total) were used in the LIRT defining the thresholds for hierarchical structure in ADL (K_partial: no limitation to partial limitation, $K_{-}$total: partial limitation to totally limited). Disability values estimated from the LIRT were fitted to a mixed-effects model to examine the manner in which the trajectories of disability varied with different subject characteristics.

Results: The findings confirmed the earliest loss in the capability to perform ADL (bathing $\left(K_{\text {-partial }}=-1.396\right)$, toileting $\left.\left(K_{\text {-partial }}=-0.904\right)\right)$ at the level of partial limitation, with an overlap of partial and totally limited (total bathing, partial dressing, partial transferring, total dressing, partial feeding, partial continence), and finally a total loss of capability for toileting, feeding, transferring, and continence $\left(K_{\text {-total }}=3.647\right)$. Disability trajectories varied with sex $(\beta=0.041, \mathrm{SE}=0.001)$, place of residence $(\beta=0.010, \mathrm{SE}=0.001)$, and marital status $(\beta=0.144, \mathrm{SE}=0.001)$. Females, individuals living in urban areas, and those who lived without a spouse had a poorer disability status.

Conclusion: The loss in the ability to perform ADL has a hierarchical structure. Subject characteristics affect trajectories of disability in the elderly Chinese population.

Keywords: Katz scale, Disability trajectories, Longitudinal item response theory, Older adult

\footnotetext{
* Correspondence: fangya@xmu.edu.cn

${ }^{1}$ State Key Laboratory of Molecular Vaccinology and Molecular Diagnostics, School of Public Health, Xiamen University, Xiang'an South Road, Xiamen 361102, China

Full list of author information is available at the end of the article
}

(c) The Author(s). 2021, corrected publication 2022. Open Access This article is licensed under a Creative Commons Attribution 4.0 International License, which permits use, sharing, adaptation, distribution and reproduction in any medium or format, as long as you give appropriate credit to the original author(s) and the source, provide a link to the Creative Commons licence, and indicate if changes were made. The images or other third party material in this article are included in the article's Creative Commons licence, unless indicated otherwise in a credit line to the material. If material is not included in the article's Creative Commons licence and your intended use is not permitted by statutory regulation or exceeds the permitted use, you will need to obtain permission directly from the copyright holder. To view a copy of this licence, visit http://creativecommons.org/ licenses/by/4.0/. The Creative Commons Public Domain Dedication waiver (http://creativecommons.org/publicdomain/zero/1. 0/) applies to the data made available in this article, unless otherwise stated in a credit line to the data. 


\section{Background}

The proportion of the global population that will be older than 60 years of age will nearly double by 2050 as life expectancy increases and birth rates decline [1]. However, longer survival times do not necessarily result in extended periods of good health. With advancing age, the elderly are prone to suffer from degenerative diseases, leading to a decline in their ability to live independently [2]. Estimates predict that 55 million elderly people will be living with a disability in China by 2025 [3]. Disabilities place a heavy burden on both families and society [4]. Timely, research-based, and effective interventions that improve the utilization of care services are urgently required to mitigate the burdens caused by disability.

Scientists generally interpret disability as the loss or a limitation of a person's ability to perform activities of daily living (ADL), an important indicator of individual health. Researchers use the Katz Index, CARS scale, and Lawton scale to assess disability $[5,6]$. However, the total score of these scales may poorly discriminate individuals with a varied disability. Furthermore, a total score can also result in a floor or ceiling effect. To minimize this deficiency, the American psychometrician Lord [7] and Danish statistician Georg Rasch [8] proposed a novel test method called item response theory (IRT). In IRT, disability in the elderly can be regarded as a potential continuum, which avoids floor and ceiling effects [9]. In the different IRT models, longitudinal item response theory (LIRT) is applied to data collected over prolonged periods. The LIRT method reduces bias when estimating the trajectory of rates of decline [10]. For example, Marc et al. [11] developed a LIRT model to characterize cognition over time which was effective at capturing the multifaceted nature of cognition and its longitudinal trajectory. LIRT is also applicable in disabilities caused by progressive disease.

It has been found that ADL are hierarchical in nature $[9,12]$. A number of researchers have applied LIRT and linear mixed models to capture the hierarchical structure of ADL and changes in the trajectory of disability over time by taking into account correlations across multiple measurements for each individual [9, 13]. As a general consensus, older adults tend to lose the ability to perform activities requiring strength in their lower extremities earlier than in activities requiring upper body strength [14-16]. Researchers have observed a pattern in the loss of ADL: females experience an initial loss in their ability to walk independently outside the home, followed by the inability to independently groom, bathe, dress, toilet, and feed themselves. Males experience a similar pattern, except that the inability to dress occurs second [17]. In addition, trajectories of disability change dynamically over time. Although controversial, a number of studies report that change in disability is sex-specific and influenced by level of education.

The present study aimed to use LIRT and a mixedeffects model to study the hierarchical structure of ability to perform ADL and the trajectories of disability of individuals over 60 years old in China. The outcomes will constitute a reference for the development of effective interventions for elderly people living with disability.

\section{Method \\ Study population}

The Chinese Longitudinal Healthy Longevity Survey (CLHLS) began in 1998 with data collection continuing in 2000, 2002, 2005, 2008-2009, 2011-2012, 2014, 2017-2018, representing eight waves in total. Investigations were conducted randomly in approximately half of the cities/counties in 23 of 31 Chinese provinces, the total population of which represented approximately $85 \%$ of the total population of China. Due to the mixed longitudinal design of CLHLS, only one-third of subjects from each wave had been studied in the previous wave, with new recruits representing the remaining participants. From 1998 to 2014, 71,130 participants were interviewed, including 16,582 centenarians, 23,207 nonagenarians, 20,135 individuals aged 65-79, and 11,206 adults aged 35-64. A total of 12,411 new subjects were included in the cohort in 2018. A more detailed analysis has been made of these [18]. The project has collected the data of individual demographic characteristics, lifestyle, physical and mental health, and survival status [19]. The present research protocol was approved by the Duke University Institutional Review Board (Pro00062871) and Peking University Biomedical Ethics Committee (IRB00001052-13074). All methods were conducted in accordance with relevant guidelines and regulations, and all participants or their legal representatives gave written informed consent.

To fully reflect the natural developmental processes of disability status prior to death, a dynamic model was constructed that spanned all eight waves in which participants older than 60 years of age were selected, with the exact age at death, including those who had at least one Katz measurement available for inclusion in the analysis. We excluded all individuals with incomplete data describing subject characteristics. The data processing process was depicted in Fig. 1.

\section{Disability status assessment}

The present study used the Katz scale to assess the ability of individuals to perform activities of daily living, which the Katz scale evaluates, including bathing, dressing, transferring, feeding, toileting, and continence, using a three-point scale (0: no limitation, 1: partial limitation, 2: totally limited) for task performance. The Chinese 


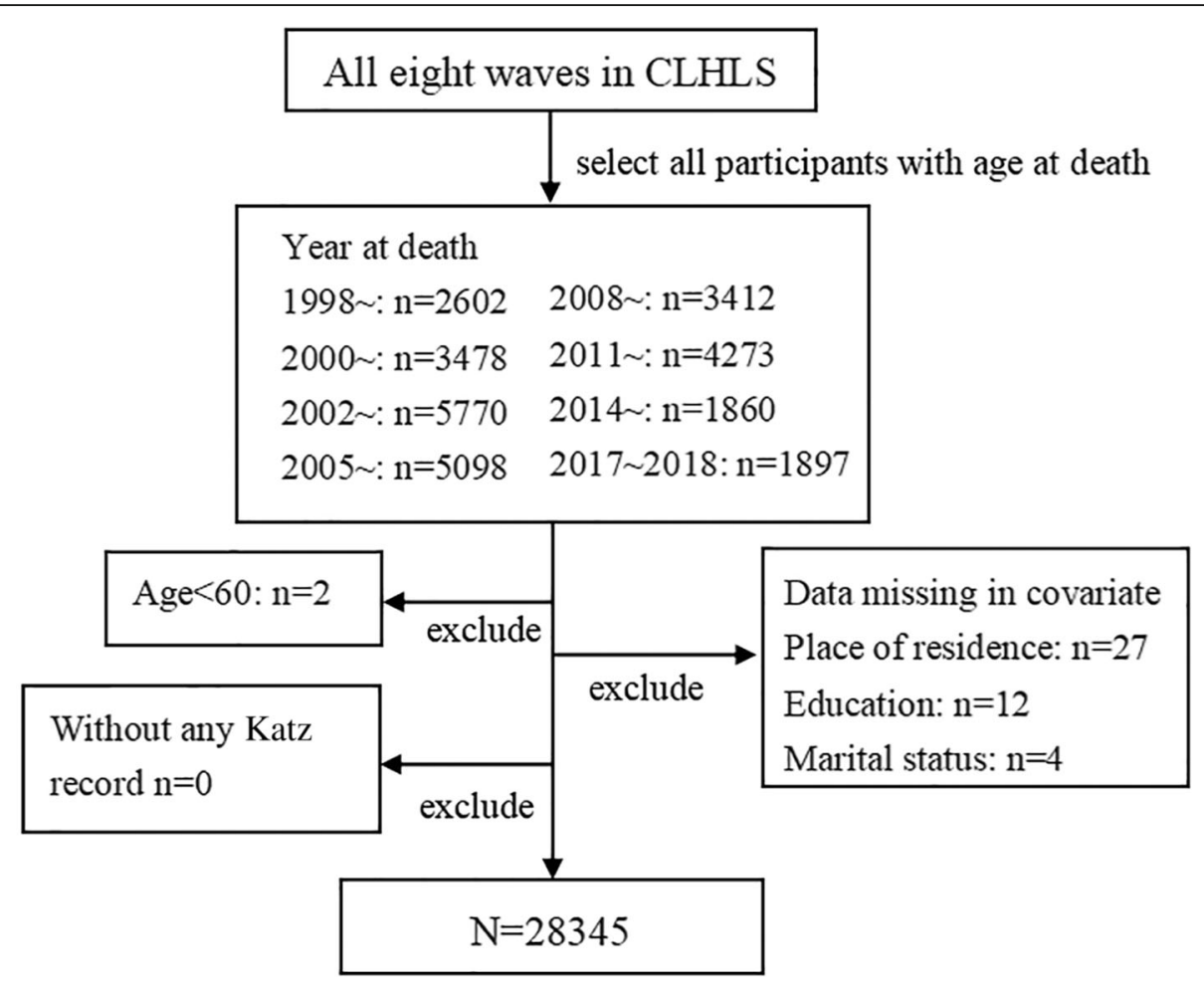

Fig. 1 Data processing process

version, which has been extensively tested in pilot interviews, has yielded reliable and valid responses [20]. Participants refusing or declining to answer a question were handled as missing cases.

\section{Model construction for the hierarchical structure of ADL}

In light of the ordered categorical responses of the Katz scale, a graded response model (GRM), proposed by Samejima [21] was selected as a generic IRT building block to relate each test item with disability status. In the GRM model for hierarchical reactions, every item had three parameters: (I) Two difficulty parameters $\left(\kappa_{\text {-partial }}\right.$ and $\left.\kappa_{\text {-total }}\right)$ defining the thresholds for change (from no limitation to partial limitation and from partial limitation to totally limited, corresponding to $\kappa_{\text {-partial }}$ and $\kappa_{\text {-total }}$, respectively). For example, bathing-partial indicated the threshold from no limitation to partial limitation for bathing. In the disability severity continuum, items with a small $\kappa$ represent activities that elderly individuals are more likely to lose the ability to perform. In the present study, difficulty parameters reveal the hierarchical structure of the ADL. (II) An item with a higher discrimination parameter $(\alpha)$ is one for which individuals could more closely be positioned at the correct disability level.

To achieve the dual goals of identification of difficulty and discrimination parameters of the Katz scale and assessment of the decline in the ability to perform ADL, we chose an LIRT model for data analysis [11]. Each individual $(s)$ response score of a specific item $(i)$ at a given time $(t)$ was recorded as $Y_{s, t}$, , while the corresponding disability status of an individual was $\theta_{s, t}$ (every six items corresponding to the same $\theta$, with larger $\theta$ values indicating a more serious disability status). In the present study, the response category of every item was $K=3$, with a cumulative probability expressed as $P_{s, t}, i$, $K=1$.

$$
\begin{aligned}
& P_{s, t, i, k}=P\left(Y_{s, t, i} \leq k \mid \theta_{s, t}\right)-P\left(Y_{s, t, i} \leq k-1 \mid \theta_{s, t}\right) \\
& \begin{aligned}
\operatorname{Logit}\left(p_{s, t, i, k}\right) & =\log \left(\frac{p_{s, t, i, k}}{1-p_{s, t, i, k}}\right)=K_{i, k}-\alpha i \theta_{s, t} k \\
& =1,2,3
\end{aligned}
\end{aligned}
$$

where $K_{i, k}$ represented the difficulty parameter of item $i$, and $\alpha_{i}$ represented the discrimination parameter of item $i$. $k$ corresponded to the selected category of the individual. The longitudinal aspect of the model was captured by setting $\theta_{s, t}=\gamma_{0, s}+\gamma_{1, s} \times t . \gamma_{0, s}$ and $\gamma_{1, s}$ represented the intercept and slope of disability status. The mean value of $\gamma_{1, s}$ was described by $\mu$, representing the mean decline of ADL over time. $\gamma_{1, s}$ was modeled as $\gamma_{1, s}$ $=\gamma_{1, s}^{\prime}+Z_{s} \beta . Z_{s}$ represented each characteristic of a sub- 
ject, including sex, age, years of education, place of residence, and marital status, $\beta$ referred to the regression coefficients of $Z_{s}$, while $\gamma_{1, s}^{\prime}$ was the intercept of $\gamma_{1, s}$. Age and years of education were zero-centered and standardized for model fitting.

The model was cast within a Bayesian framework and then implemented using a Markov Chain Monte Carlo (MCMC) method. The posterior 95\% credible interval for each parameter was displayed with posterior credible intervals (Q2.5, Q97.5). A weak information prior distribution was adopted in all parameters except $\gamma_{0, s}$ [22], which used an independent $N(0,1)$ prior distribution. The slope $\gamma_{1, s}$ selected a hierarchical prior distribution.

\section{Trajectories of disability}

To determine trajectories of disability, the time between interview and death was used as the independent variable $(t)$ and the disability level $(\theta)$ of the elderly individual, obtained using the aforementioned LIRT, represented the dependent variable (scale to $[-3,3]$ ). A mixed-effects model [23] was used to analyze changes in function over time. The model is shown below:

$$
\begin{aligned}
& \theta_{s, t}=\eta_{1 s,}+\eta_{2 s} t_{s}+e_{s, t} \cdot e_{s, t} \sim N\left(0, \sigma^{2}\right) \\
& \eta_{1 s=\beta_{1}+b_{1 s}}\left(b_{1 s}, b_{2 s}\right) \sim M V N(0, \Sigma) \\
& \eta_{2 s=\beta_{2}+b_{1 s}}
\end{aligned}
$$

where $\theta_{s, t}$ was the elderly individual's potential disability at time $t, \eta_{1 s}$ was the intercept when $t$ was equal to 0 , while $\eta_{2 s}$ reflected changes in $\theta_{s, t}$ over time. The parameter vector $\left(b_{1 s}, b_{2 s}\right)$ was multivariate normally distributed with mean of zero and a $2 \times 2$ variancecovariance matrix $\Sigma$. Using this process, $t$ was considered level one, $s$ as level two, and all subject-specific covariates (sex, place of residence, marital status, sex* place of residence, age, years of education, sex"marital status) were included in the model as adjustment factors.

The LIRT methodology was performed using OpenBUGS software while calculations for the mixed-effects model were conducted using MLwiN software. Pre and post-data processing were completed in the $R_{3.5 .3}$ environment. OpenBUGS software used thin $=1$ and 1000 iterations after a 4000 burn-in.

\section{Results}

\section{Subject characteristics}

The exact age at death was recorded for 28,390 individuals for which there was at least one Katz record. After excluding 45 individuals with incomplete covariate data (a missing ratio of $0.15 \%$ ), 28,345 participants were included in the study. The median elapsed time between the initial and final visit was 3 years (range: $0-19$ years). Females accounted for approximately $60 \%$ of the study population (Table 1). Mean age was 91.3 years, ranging from 60 years to 122 years. Regarding years of education, $70.7 \%$ of participants had never been to school, and more than $90.6 \%$ had a low level of education - less than 5 years. The majority of participants (63.1\%) lived in rural areas, the remaining $36.9 \%$ residing in urban areas. Approximately $80 \%$ of the participants did not live with a spouse.

\section{Discrimination parameters}

Table 2 displays the posterior distributions of the discrimination parameters. The posterior means of ADL items were ranked from toileting, transferring, dressing, feeding, bathing, and continence (range: 1.125 to 4.124).

\section{Difficulty parameters}

The hierarchical structure of declining ability to perform ADL, provided by the estimated difficulty parameters, is presented in Table 3. Firstly, with a range between 1.396 and 3.647, we confirmed that loss in the ability to perform ADL began with bathing -partial $_{\text {and ended with }}$ continence $_{\text {-total }}$. In particular, bathing-partial $\left(\kappa_{\text {-partial: }}\right.$ : 1.396 (standard error (SE), 0.003)) and toileting-partial $\left(\kappa_{\text {-partial: }}-0.904\right.$ (SE, 0.006)) were observed in succession. The last item for which the elderly required partial assistance was continence. Bathing was the first task that was restricted at the level of totally limited $\left(\kappa_{\text {-total }}:-0.374\right.$ (SE, 0.003)). Finally, at the end of the structure, feeding $\left(\kappa_{\text {-total }}: 3.440(\mathrm{SE}, 0.004)\right)$, transferring $\left(\kappa_{\text {-total }}: 3.454\right.$ (SE, $0.008)$ ), and continence $\left(\kappa_{\text {-total }}: 3.647\right.$ (SE, 0.013)) were totally limited.

\section{Effect of subject-specific characteristics on the rate of decline}

Table 4 displays the regression coefficients of the subject characteristics for individual slopes $\gamma_{1, s}$. Sex, years of education, place of residence, marital status, and age displayed significant associations with slope values. The value can only be interpreted in relative terms (not the risk of disability), such that males, older age, fewer years of education, urban residence, and living without a spouse was associated with a faster decline. The posterior mean of the slope parameter $\mu$ was 0.857 (2.5 and $97.5 \%$ quantiles $[0.824,0.891], \mathrm{SE}=0.003)$, indicating that individual disability increased by 0.857 units per year.

\section{Trajectories of disability in the mixed-effects model}

Trajectories of disability varied with $\operatorname{sex}(\beta=0.041, \mathrm{SE}=$ $0.001)$, place of residence $(\beta=0.010, \mathrm{SE}=0.001)$, and marital status $(\beta=0.144, \mathrm{SE}=0.001)$. Females, individuals residing in urban areas, and those living without a spouse had a poorer disability status. Further crossgroup analysis in Fig. 2 indicates that, compared with 
Table 1 Baseline characteristics of the study population

\begin{tabular}{llll}
\hline & No. & $\%$ & Mean (SD) \\
\hline Gender & 11,280 & & \\
Male & & $39.8 \%$ & \\
$\quad$ Female & 17,065 & $60.2 \%$ & \\
Place of residence & & $36.9 \%$ & \\
$\quad$ Urban & 10,448 & $63.1 \%$ & \\
$\quad$ Rural & 17,897 & & \\
Current marital status & & $19.2 \%$ & \\
$\quad$ With spouse & 5444 & $80.8 \%$ & $1.4(2.9)$ \\
$\quad$ Without spouse & 22,901 & & \\
Age & & & \\
$\quad$ Mean (SD) & & & \\
Years of education & & & \\
$\quad$ Mean (SD) & & &
\end{tabular}

males living in rural areas (mean $=-0.219, \mathrm{SE}=0.001$ ), the disability status of males living in urban areas (mean $=-0.163, \mathrm{SE}=0.001)$, females living in rural areas (mean $=-0.124, \mathrm{SE}=0.001)$, and females living in urban areas $($ mean $=-0.085, \mathrm{SE}=0.001)$ declined progressively. As displayed in Fig. 3, compared with males living with a spouse (mean $=-0.265, \mathrm{SE}=0.001$ ), the disability status of males living without (mean $=-0.249, \mathrm{SE}=0.002)$, females living with a spouse (mean $=-0.164, \mathrm{SE}=0.001$ ), and females living without a spouse (mean $=-0.099$, $\mathrm{SE}=0.001$ ) became sequentially worse. Detailed disability status and cross-group characteristics are displayed in Supplementary Table S1. After a brief fluctuation in the 15-19 years prior to death, the function displays a deterioration from the 15th year.

\section{Discussion}

We studied the natural history of disability over the last 19 years of life in the CLHLS cohort. We provided a synthetic hierarchy of the Katz scale's rating of ADL performance and described the trajectories of disability preceding death. As is well known, greater severity of disability in the elderly results in additional burden on caregivers [24]. Therefore, preventing or slowing the

Table 2 Posterior means and 95\% credible intervals of the discrimination parameters for items in Katz scale

\begin{tabular}{lllll}
\hline & Mean & SE & Q2.5 & Q97.5 \\
\hline Bathing & 1.291 & 0.003 & 1.261 & 1.317 \\
Dressing & 2.877 & 0.007 & 2.810 & 2.917 \\
Toileting & 4.124 & 0.015 & 3.984 & 4.286 \\
Transferring & 3.682 & 0.007 & 3.565 & 3.783 \\
Continence & 1.125 & 0.003 & 1.077 & 1.168 \\
Feeding & 2.137 & 0.004 & 2.071 & 2.197 \\
\hline
\end{tabular}

Table 3 Posterior means and 95\% credible intervals of the difficulty parameters $(k)$ for items in Katz scale

\begin{tabular}{lllll}
\hline & Mean & SE & Q2.5 & Q97.5 \\
\hline Bathing-partial & -1.396 & 0.003 & -1.433 & -1.364 \\
Toileting-partial & -0.904 & 0.006 & -0.953 & -0.843 \\
Bathing-total & -0.374 & 0.003 & -0.406 & -0.366 \\
Dressing-partial $_{\text {Transferring-partial }}$ & -0.277 & 0.004 & -0.315 & -0.238 \\
Dressing-total $_{\text {Feeding-partial }}$ & 0.053 & 0.004 & -0.082 & -0.017 \\
Continence-partial & 0.917 & 0.004 & 0.441 & 0.520 \\
Toileting-total & 1.371 & 0.005 & 0.884 & 0.962 \\
Feeding-total $_{\text {Transferring-total }}$ & 3.348 & 0.009 & 1.324 & 1.409 \\
Continence-total & 3.440 & 0.004 & 3.238 & 3.478 \\
\hline
\end{tabular}

occurrence of disability in the elderly should be a key national focus. Unfortunately, few international studies have examined the natural history of disability in the elderly. Governments routinely advocate preventive strategies for health problems, and as such, geriatric medicine must evolve to intervene at an earlier stage of the disability process to be more effective. To date, a number of research studies have demonstrated a positive effect of primary prevention on dependence morbidity [25-27]. For the elderly, disability is a primary dimension of health and function, and it acts as an indicator or guideline for developing health policies for this age group [28]. The present study provides foundational evidence upon which to formulate early intervention policies for preventing disability in the elderly.

\section{Item discrimination}

According to the guidelines of Baker [29] for a normal ogive model, the discrimination value for continence was moderate, with all other items very high. Poor discrimination refers to a task or activity (i.e., scale items) that proves unresponsive to changes in a particular

Table 4 Regression coefficients for the individual slopes $\gamma_{1, s}$ in LIRT

\begin{tabular}{lllll}
\hline & Mean & SE & Q2.5 & Q97.5 \\
\hline Male/Female & 0.102 & 0.001 & 0.089 & 0.117 \\
Baseline Age & 0.889 & 0.000 & 0.883 & 0.894 \\
Urban/Rural & -0.591 & 0.003 & -0.614 & -0.566 \\
Years of Education & -0.730 & 0.002 & -0.743 & -0.718 \\
Marital Status & 0.056 & 0.003 & 0.021 & 0.078 \\
\hline $\begin{array}{l}\text { Note: The binary covariates were coded as sex [0: male, 1: female], place of } \\
\text { residence [0: urban, 1: rural], marital status [0: with a spouse, 1: without a }\end{array}$ \\
$\begin{array}{l}\text { spouse]. Years of education and baseline age were zero-centered and } \\
\text { standardized for model fitting }\end{array}$
\end{tabular}




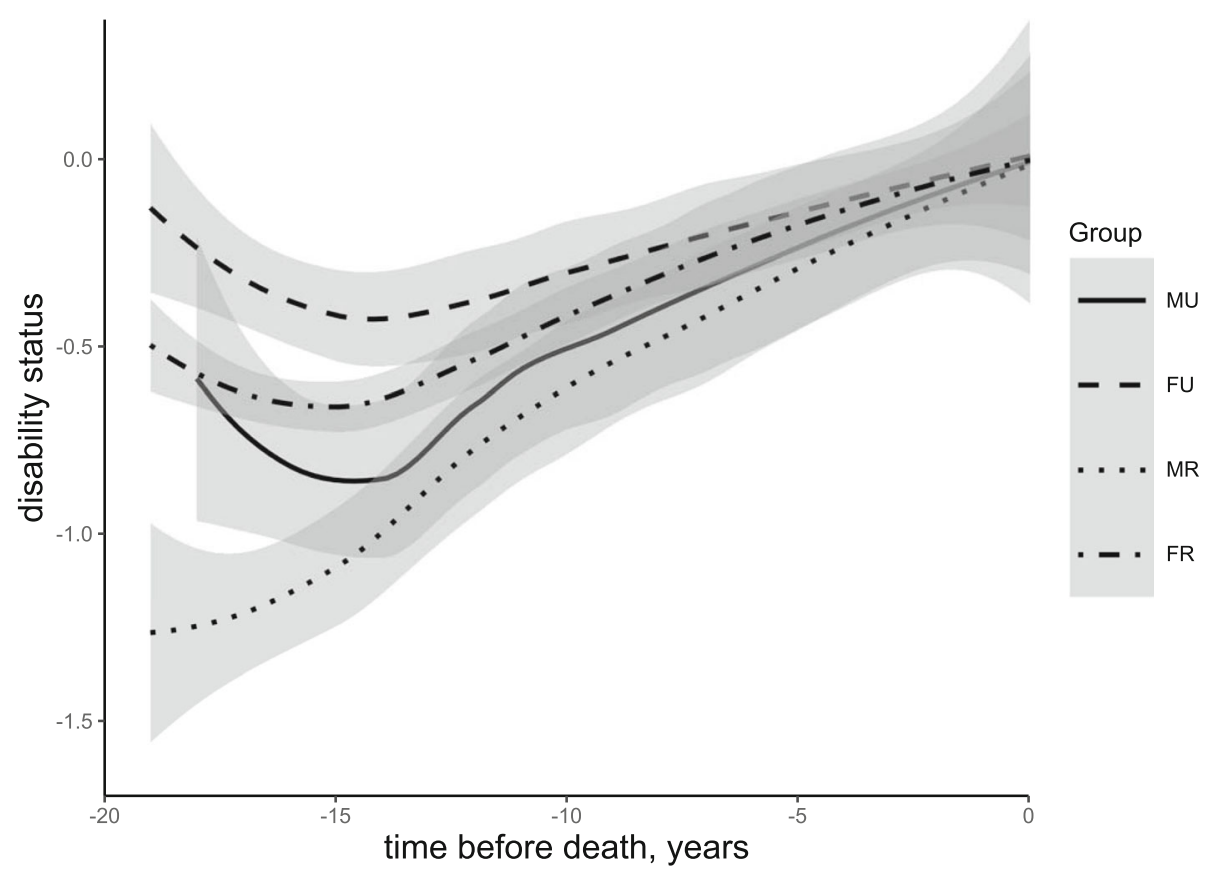

Fig. 2 Nineteen-year mean trajectories of disability preceding death grouped by gender*place of residence. Note: MU means males living in urban, FU means females living in urban, MR means males living in rural, FR means females living in rural. Adjusted for age, marital status and years of education

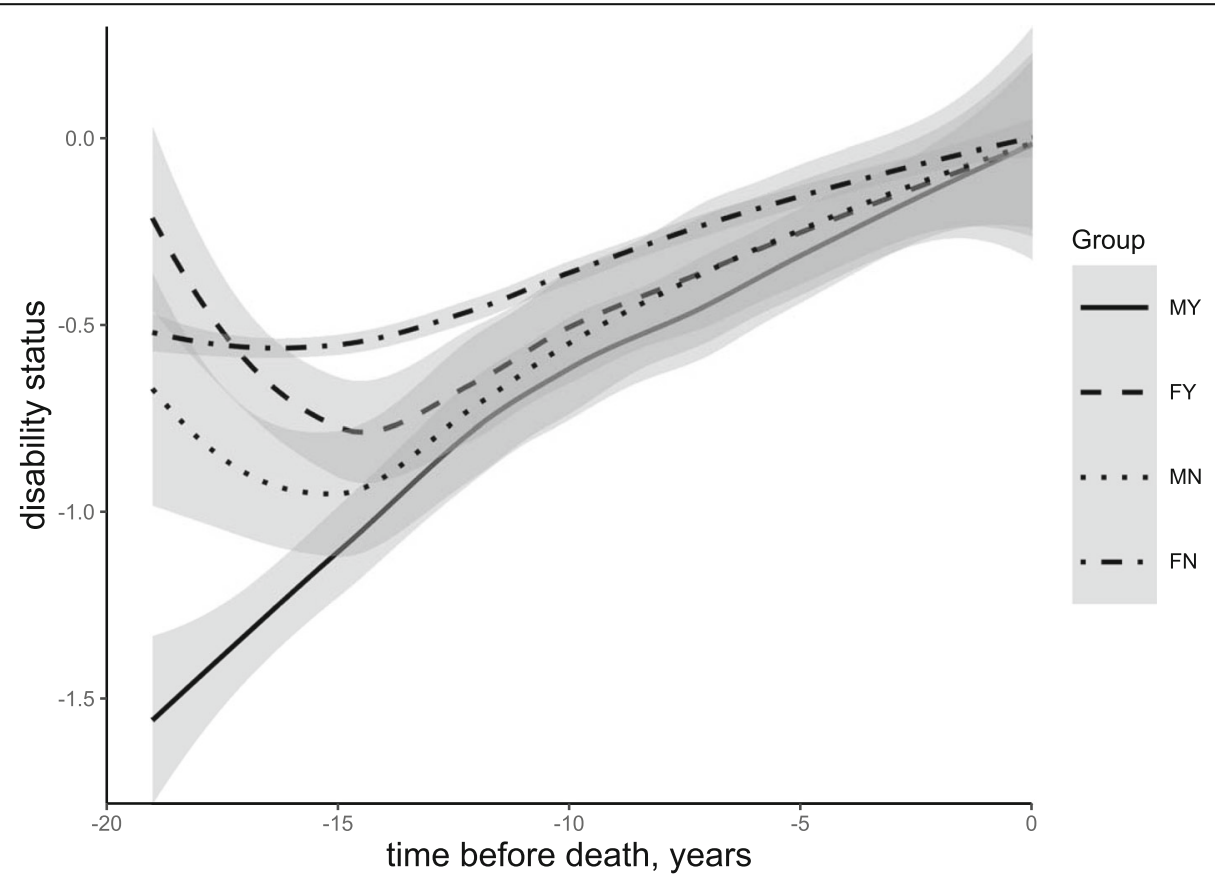

Fig. 3 Nineteen-year mean trajectories of disability preceding death grouped by gender*marital status. Note: MY means males living with a spouse, FY means females living with a spouse, MN means males living without spouse, FN means females living without spouse. Adjusted for age, place of residence and years of education 
person's level of disability. In the present research, the discrimination values of all items were greater than 0.3 [30], demonstrating that the Katz scale is applicable to the Chinese elderly population as a whole. Similarly, other researchers have found the same ranking of parameters (toileting $>$ transferring $>$ dressing) in a twoparameter IRT model $[31,32]$. In previous calculations of parameters between ADL items, it was generally believed that discrimination for toileting, dressing, and bathing was greater $[33,34]$. However, in the present study, there was a moderate discriminatory effect for bathing. Saliba et al. [34] divided elderly people aged over 65 years into two groups (65-84 years and $\geq 85$ years) and found that bathing displayed a smaller degree of discrimination in the older age group when model fitting. The very high age range in this study may be the reason that bathing could not more effectively distinguish different levels of disability.

\section{Hierarchical structure of ADL}

The continuum of declining ability to perform ADL began with bathing-partial and ended with continence-total. As noted in previous publications [17, 35-37], bathing was the first ADL to deteriorate, defined by Katz et al. as the threshold of disability. In the present study, the difficulty parameter between bathing-partial and bathing-total was only 1.022, confirming that bathing was the first ADL to be lost among the elderly. Researchers have reported that bathing is the first ADL that both elderly Americans and Chinese have difficulty in performing [14]. However, the bathing task was informative only in the range of low capability, so partial and total limitation in bathing occurred when the elderly were only slightly disabled.

The second ADL to be lost was toileting-partial. Of the six items explored here, the behavior of the toileting item was peculiar. The distance on the continuum between its partial and total limitation thresholds was considerably higher (4.252) than the other activities (ranging from 0.759 (dressing) to 3.507 (transferring)). Furthermore, its discriminative capability was very high, indicating that the item correctly discriminates between individuals at the two levels of disability.

\section{Factors affecting deteriorating ability status}

The Bayesian methodology allowed longitudinal slope estimates to remain vague for subjects with little (or no) follow-up time. We fitted our model on all participants and concluded that males, greater age, fewer years of education, living in rural areas or without a spouse were associated with a faster deterioration in the ability to perform ADL. We discovered that older females had a higher level of disability, but their functional capabilities deteriorated at a slower rate. As a result, there are a larger proportion of dependent women within the elderly population in China. Education has always been considered a factor that slows aging and decline in ability [38-40]. The probable reason is that people with lower levels of education pay less attention to their physical health, not to mention the prevention of chronic disease. In addition, this phenomenon is more common in rural areas. It has long been argued that marital status, as a defining feature of the social environment, affects an individual's risk of disability [41]. Marital status is significantly associated with physical disability $[42,43]$, and marital closeness moderates the negative psychological effects of high levels of disability on depression, anxiety, and self-esteem [44].

\section{Trajectories of disability}

The estimated trajectories of disability highlighted that the extent of disability became progressively serious as death approached. Trajectories of disability at the end of life are quite variable $[45,46]$. In the mixed-effects model, females, living in urban areas, and living without a spouse had worse ADL status. Interestingly, disability status was better in rural areas. It may be that rural medical services are relatively inaccessible, and older adults become frailer at a younger age dying earlier, so the remaining elderly are in better condition [47]. Overall, differentiating the expected trajectories and related needs would help tailor strategies and programs to improve elderly care prior to death.

\section{Strengths and weaknesses}

The innovative feature of the present study was that it relied on a longitudinal analysis of long-term follow-up data from a substantial sample of the general elderly population. Moreover, the LIRT and mixed-effects models allowed a capture of the multifaceted nature of disability. The LIRT also allowed us to estimate item and disability distribution parameters, as the data were from a longitudinal cohort study. In addition, the correlation between the subject-specific characteristics and the slope of deterioration was embedded in the same model.

Three limitations of this study should be noted. It has been suggested that instrumental ADL (IADL) and ADL have a hierarchical relationship, with older adults first declining in IADL functionality $[48,49]$. However, there were no IADL items investigated in this survey, preventing exploration of the hierarchy of ADL and IADL disability. We found that OpenBUGS is a time-consuming statistical software package when adding too many covariates in the process of implementing MCMC. Comorbidities may also affect disability of the elderly. As an exploratory analysis, we have not considered chronic diseases for the time being, but we will look for more efficient software to research the influence of chronic 
diseases and other influencing factors in subsequent studies. Unavoidably, there may also have been investigation bias and survivor bias during the follow-up period.

\section{Conclusion}

In conclusion, toileting and bathing are promising domains for detecting early signs of disability in the elderly Chinese population. At the same time, toileting and transferring are more discriminative than other ADL items. LIRT methodology and the mixed-effects model, as applied here in an elderly population, are suitable methods to jointly capture the multifaceted nature of disability and its rate of change. As a result, we found that males, those of older age, fewer years of education, living in rural areas, and living without a spouse often decline faster in their ability to perform ADL. However, females, individuals who live in urban areas and those without a spouse had a lower ability to perform ADL. Therefore, we recommend a reasonable allocation of health resources toward mitigating declining ability and encourage the widowed elderly to engage in more social activities. Furthermore, health interventions are required to address deficits in the home bathing environment, especially in developing countries such as China.

\section{Abbreviations}

ADL: Activities of daily living; IADL: Instrumental activities of daily life; IRT: Item response theory; LIRT: Longitudinal item response theory; CLHL S: Chinese longitudinal healthy longevity survey; GEM: Graded response model

\section{Supplementary Information}

The online version contains supplementary material available at https://doi. org/10.1186/s12877-021-02460-y.

Additional file 1: Table S1. Disability status of the elderly with crossgroup characteristics.

\section{Acknowledgements}

We thank the Center for Healthy Aging and Development Studies of Peking University for providing the data.

\begin{abstract}
Authors' contributions
Study concept and design: Yaofeng Han, Jihui Xue. Acquisition of data: Jihui Xue, Wei Pei. Analysis and interpretation of data: Jihui Xue. Drafting of the manuscript: Yaofeng Han, Jihui Xue. Critical revision of the manuscript for important intellectual content: Yaofeng Han, Ya Fang. All authors read and approved the final manuscript.
\end{abstract}

\section{Funding}

Fujian Provincial Department of Science and Technology (2019 J01038). The funder played no role in study design, data collection, and analysis, the decision to publish, or preparation of the manuscript.

\section{Availability of data and materials}

The raw data is available online (https://opendata.pku.edu.cn). Researchers can obtain these data after submitting a data use agreement to the CLHLS team.

\section{Declarations}

\section{Ethics approval and consent to participate}

The study design was approved by the Duke University Institutional Review Board and Peking University Biomedical Ethics Committee. All methods were carried out in accordance with relevant guidelines and regulations, and all participants gave written informed consent.

Consent for publication

Not applicable.

\section{Competing interests}

Not applicable.

\section{Author details}

'State Key Laboratory of Molecular Vaccinology and Molecular Diagnostics, School of Public Health, Xiamen University, Xiang'an South Road, Xiamen 361102, China. ${ }^{2}$ Center for Aging and Health Research School of Public Health, Xiamen University, Xiamen, China.

Received: 1 June 2021 Accepted: 10 September 2021

Published online: 02 October 2021

\section{References}

1. Kontis V, Bennett JE, Mathers CD, Li G, Foreman K, Ezzati M. Future life expectancy in 35 industrialised countries: projections with a Bayesian model ensemble. Lancet. 2017;389(10076):1323-35. https://doi.org/10.1016/S01406736(16)32381-9.

2. Guzman-Castillo M, Ahmadi-Abhari S, Bandosz P, Capewell S, Steptoe A, Singh-Manoux $A$, et al. Forecasted trends in disability and life expectancy in England and Wales up to 2025: a modelling study. Lancet Public Health. 2017;2(7):e307-e13. https://doi.org/10.1016/S2468-2667(17)30091-9.

3. Baiyu Zhou J, Yu P. Pay attention to the prevention of disability in the elderly. Chinese J Geriatr. 2019;38(10):1075-6.

4. Heid AR, Zarit SH, Van Haitsma K. Older adults' influence in family care: how do daughters and aging parents navigate differences in care goals? Aging Ment Health. 2016;20(1):46-55. https://doi.org/10.1080/13607863.2015.104 9117.

5. Mcdowell I. Measuring health: a guide to rating scales and questionnaires Oxford University press; 2006. https://doi.org/10.1093/acprof:oso/97801951 65678.001 .0001

6. Brody EMJ. Assessment of Older People: Self-Maintaining and Instrumental Activity of Daily Living. Gerontologist. 1988;13(1):64-8.

7. Lord FMA. Theory of Test Scores: Psychometric Society; n.d.

8. Rasch G. Studies in mathematical psychology: I. Probabilistic models for some intelligence and attainment tests 1960.

9. Edjolo A, Proust-Lima C, Delva F, Dartigues JF, Pérès K. Natural history of dependency in the elderly: a 24-year population-based study using a longitudinal item response theory model. Am J Epidemiol. 2016;183(4):27785. https://doi.org/10.1093/aje/kwv223.

10. Crane PK, Narasimhalu K, Gibbons LE, Mungas DM, Haneuse S, Larson EB, et al. Item response theory facilitated cocalibrating cognitive tests and reduced bias in estimated rates of decline. J Clin Epidemiol. 2008;61(10): 1018-27.e9.

11. Vandemeulebroecke M, Bornkamp B, Krahnke T, Mielke J, Monsch A, Quarg P. A longitudinal item response theory model to characterize cognition over time in elderly subjects. CPT Pharmacometrics Syst Pharmacol. 2017;6(9): 635-41. https://doi.org/10.1002/psp4.12219.

12. Kempen Gl, Suurmeijer TP. The development of a hierarchical polychotomous ADL-IADL scale for noninstitutionalized elders. Gerontologist. 1990;30(4):497-502. https://doi.org/10.1093/geront/30.4.497.

13. Arab L, Biggs ML, O'Meara ES, Longstreth WT, Crane PK, Fitzpatrick AL. Gender differences in tea, coffee, and cognitive decline in the elderly: the cardiovascular health study. J Alzheimer's Dis. 2011;27(3):553-66. https://doi. org/10.3233/JAD-2011-110431.

14. Fong JH, Feng J. Comparing the loss of functional independence of older adults in the U.S. and China. Arch Gerontol Geriatr. 2018;74:123-7.

15. Dunlop DD, Hughes SL, Manheim LM. Disability in activities of daily living: patterns of change and a hierarchy of disability. Am J Public Health. 1997; 87(3):378-83. https://doi.org/10.2105/AJPH.87.3.378. 
16. Ferrucci L, Guralnik JM, Cecchi F, Marchionni N, Salani B, Kasper J, et al. Constant hierarchic patterns of physical functioning across seven populations in five countries. The Gerontologist. 1998;38(3):286-94. https:// doi.org/10.1093/geront/38.3.286.

17. Delva F, Edjolo A, Pérès K, Berr C, Barberger-Gateau P, Dartigues JF. Hierarchical structure of the activities of daily living scale in dementia. J Nutr Health Aging. 2014;18(7):698-704. https://doi.org/10.1007/s12603-0140503-7.

18. Studies $\mathrm{CfHAaD}$. The Chinese Longitudinal Healthy Longevity Survey (CLHL S)-Longitudinal Data (1998-2018). DRAFT VERSION ed: Peking University Open Research Data Platform; 2020.

19. Zeng Y, Poston DL, Vlosky DA, Gu D. Healthy longevity in China: demographic, socioeconomic, and psychological dimensions. Springer Ebooks. 2008;63(3):312-3.

20. Yi Z, Vaupel JW, Zhenyu X. The healthy longevity survey and the active life expectancy of the oldest old in China. Population. 2001;13(1):95-116.

21. Samejima F. Estimation of latent ability using a response pattern of graded scores. Psychometrika. 1968;34(1):139.

22. Bornkamp B. Functional uniform priors for nonlinear modeling. Biometrics. 2012;68(3):893-901. https://doi.org/10.1111/j.1541-0420.2012.01747.x.

23. Fox J-P, den Hout Ardo $V$, et al. Longitudinal mixed-effects models for latent cognitive function. Stat Model. 2015;15(4):366-87. https://doi.org/10.1177/14 $71082 \times 14555607$.

24. Rezende TC, Coimbra AM, Costallat LT, Coimbra IB. Factors of high impacts on the life of caregivers of disabled elderly. Arch Gerontol Geriatr. 2010; 51(1):76-80. https://doi.org/10.1016/j.archger.2009.08.003.

25. Gill TM, Baker DI, Gottschalk M, Peduzzi PN, Allore H, Byers A. A program to prevent functional decline in physically frail, elderly persons who live at home. N Engl J Med. 2002;347(14):1068-74. https://doi.org/10.1056/NEJMoa 020423.

26. Machacova K, Vankova H, Volicer L, Veleta P, Holmerova I. Dance as prevention of late life functional decline among nursing home residents. J Appl Gerontol. 2017;36(12):1453-70. https://doi.org/10.1177/07334648 5602111.

27. Laffon de Mazières C, Morley JE, Levy C, Agenes F, Barbagallo M, Cesari M, et al. Prevention of functional decline by reframing the role of nursing homes? J Am Med Dir Assoc. 2017;18(2):105-10. https://doi.org/10.1016/j.ja mda.2016.11.019.

28. Giacomin KC, Firmo JO. Old age, disability and care in public health. Cien Saude Colet. 2015;20(12):3631-40. https://doi.org/10.1590/1413-812320152 012.11752014

29. Baker FB. The basics of item response theory. College Park: ERIC Clearinghouse on Assessment and Evaluation; 2001.

30. Lou MF, Dai YT, Huang GS, Yu PJ. Identifying the most efficient items from the Mini-mental state examination for cognitive function assessment in older Taiwanese patients. J Clin Nurs. 2007;16(3):502-8. https://doi.org/1 0.1111/j.1365-2702.2005.01551.x.

31. Hong I, Lee MJ, Kim MY, Park HY. Item-level psychometrics of the ADL instrument of the Korean National Survey on persons with physical disabilities. Qual Life Res. 2017;26(10):2867-75. https://doi.org/10.1007/s1113 6-017-1637-y.

32. Spector WD, Fleishman JA. Combining activities of daily living with instrumental activities of daily living to measure functional disability. J Gerontol B Psychol Sci Soc Sci. 1998;53(1):S46-57. https://doi.org/10.1093/ geronb/53B.1.S46.

33. Finlayson M, Mallinson T, Barbosa VM. Activities of daily living (ADL) and instrumental activities of daily living (IADL) items were stable over time in a longitudinal study on aging. J Clin Epidemiol. 2005;58(4):338-49. https://doi. org/10.1016/j.jclinepi.2004.10.008.

34. Saliba D, Orlando M, Wenger NS, Hays RD, Rubenstein LZ. Identifying a short functional disability screen for older persons. J Gerontol A Biol Sci Med Sci. 2000;55(12):M750-6. https://doi.org/10.1093/gerona/55.12.M750.

35. Morris JN, Berg K, Fries BE, Steel K, Howard EP. Scaling functional status within the interRAI suite of assessment instruments. BMC Geriatr. 2013;13(1): 128. https://doi.org/10.1186/1471-2318-13-128

36. Gerrard P. The hierarchy of the activities of daily living in the Katz index in residents of skilled nursing facilities. J Geriatr Phys Ther. 2013;36(2):87-91. https://doi.org/10.1519/JPT.0b013e318268da23.

37. Jagger C, Arthur AJ, Spiers NA, Clarke M. Patterns of onset of disability in activities of daily living with age. J Am Geriatr Soc. 2001;49(4):404-9. https:// doi.org/10.1046/j.1532-5415.2001.49083.x.
38. Tsai Y. Education and disability trends of older Americans, 2000-2014. J Public Health (Oxf). 2017:39(3):447-54.

39. Chen S, Qin J, Li Y, Wei Y, Long B, Cai J, et al. Disability and Its Influencing Factors among the Elderly in a County, Guangxi Province, China. Int J Environ Res Public Health. 2018;15(9):1967.

40. Demura S, Sato S, Minami M, Kasuga K. Gender and age differences in basic $\mathrm{ADL}$ ability on the elderly: comparison between the independent and the dependent elderly. J Physiol Anthropol Appl Hum Sci. 2003;22(1):19-27. https://doi.org/10.2114/jpa.22.19.

41. Hughes ME, Waite LJ. Marital biography and health at mid-life. J Health Soc Behav. 2009:50(3):344-58. https://doi.org/10.1177/002214650905000307.

42. Liu H, Zhang Z. Disability trends by marital status among older Americans, 1997-2010: an examination by gender and race. Popul Res Policy Rev. 2013; 32(1):103-27. https://doi.org/10.1007/s11113-012-9259-0.

43. Kail BL. Marital status as a moderating factor in the process of disablement. J Aging Health. 2016;28(1):139-64. https://doi.org/10.1177/089826431 5589572.

44. Mancini AD, Bonanno GA. Marital closeness, functional disability, and adjustment in late life. Psychol Aging. 2006;21(3):600-10. https://doi.org/10.1 037/0882-7974.21.3.600.

45. Gill TM, Gahbauer EA, Han L, Allore HG. Trajectories of disability in the last year of life. N Engl J Med. 2010;362(13):1173-80. https://doi.org/10.1056/ NEJMoa0909087.

46. Lunney JR, Lynn J, Foley DJ, Lipson S, Guralnik JM. Patterns of functional decline at the end of life. JAMA. 2003;289(18):2387-92. https://doi.org/10.1 001/jama.289.18.2387.

47. Ting L. Growth curve trajectories of elderly People's health indicators in China: cohort variations and rural-urban disparities. Population Res. 2014; 38(02):18-35

48. Spector WD, Katz S, Murphy JB, Fulton JP. The hierarchical relationship between activities of daily living and instrumental activities of daily living. J Chronic Dis. 1987;40(6):481-9. https://doi.org/10.1016/0021-9681(87)90004-X.

49. $X u$ W, Li YX, Hu Y, Wu C. Association of Frailty with recovery from disability among community-dwelling Chinese older adults: China health and retirement longitudinal study. BMC Geriatr. 2020;20(1):119. https://doi.org/1 0.1186/s12877-020-01519-6.

\section{Publisher's Note}

Springer Nature remains neutral with regard to jurisdictional claims in published maps and institutional affiliations.
Ready to submit your research? Choose BMC and benefit from:

- fast, convenient online submission

- thorough peer review by experienced researchers in your field

- rapid publication on acceptance

- support for research data, including large and complex data types

- gold Open Access which fosters wider collaboration and increased citations

- maximum visibility for your research: over $100 \mathrm{M}$ website views per year

At $\mathrm{BMC}$, research is always in progress.

Learn more biomedcentral.com/submissions 